http://journal.nafo.int

J. Northw. Atl. Fish. Sci., Vol. 7: 137-144

\title{
Effect of Allocation and Stratification Strategies on Precision of Survey Abundance Estimates for Atlantic Cod (Gadus morhua) on the Eastern Scotian Shelf
}

\author{
S. Gavaris \\ Department of Fisheries and Oceans, Biological Sciences Branch \\ Biological Station, St. Andrews, New Brunswick, Canada E0G 2X0 \\ and \\ S. J. Smith \\ Department of Fisheries and Oceans, Biological Sciences Branch \\ Bedford Institute of Oceanography, P. O. Box 1006 \\ Dartmouth, Nova Scotia, Canada, B2Y 4A2
}

\begin{abstract}
One of the primary uses of bottom-trawl survey data, with respect to fisheries management, is the estimation of abundance of the species involved. Stratified-random surveys have been conducted on the eastern Scotian Shelf since 1970. The precision of abundance estimates for Atlantic cod (ages 5-12) from these surveys was found to be inferior to what would have been obtained if simple random surveys had been conducted. These results were primarily due to suboptimal allocation of stations to strata. Historical data were used to devise alternative sampling strategies. This analysis indicated that the number of strata could be reduced considerably without loss of precision. An additional and important benefit of the smaller number of strata would be increased flexibility for allocation. With the present level of sampling, it would be necessary to reduce the number of strata to achieve proportional allocation of stations or to approximate optimal allocation.
\end{abstract}

\section{Introduction}

The potential value of using research-vessel survey-data for fisheries management was recognized in the late 1960's (e.g. Grosslein, 1969). As one of the first steps toward establishing standardized and coordinated surveys throughout the Convention Area of the International Commission for the Northwest Atlantic Fisheries (ICNAF), the Standing Committee on Research and Statistics (STACRES) endorsed the use of stratified-random survey designs (ICNAF, 1970). The advantages of stratified-random designs for surveys were initially reviewed by Grosslein (1969, MS $1969)$ and more recently by Doubleday (1981).

The main reason for preferring the stratifiedrandom design over the previously-used line-transect and systematic surveys was that the former allows for estimating the precision of the estimates of total abundance whereas the latter designs do not. The main advantage of stratified sampling over simple random sampling, apart from spreading the sampling over the study area, is that sampling rates (sample allocation) can be varied between strata to improve the precision of the abundance estimates. Judicious attention to strata construction and sample allocation can result in a stratified design which gives more precise estimates of population abundance than would be obtained by a comparable simple random design.

In this study, the stratification scheme, which is currently used for estimating the abundance of Atlantic cod (Gadus morhua) on the eastern Scotian Shelf (NAFO Div. 4Vs and 4W), is evaluated with respect to the gain in precision over what would have been obtained if a simple random design had been used. The evaluation is focused on estimates of abundance of adult cod (ages 5-12). Possible improvements in precision of the estimators, by changing the sample allocation scheme and/or the stratification scheme, are also investigated. Such a study is particularly relevant for this cod stock, because recent assessments for management purposes have relied extensively on abundance estimates from the groundfish surveys (Sinclair and Gavaris, MS 1985; Gagné et al., MS 1983, MS 1984).

\section{Method of Evaluation}

The method of Sukhatme and Sukhatme (1970, p. 91) was used to estimate the gain in precision due to stratification relative to simple random sampling. For arbitrary allocation of stations among strata, the difference 
between the variance from simple random sampling, $V\left(\bar{y}_{\mathrm{f}}\right)$, and the variance for stratified sampling, $V\left(\bar{y}_{s}\right)$, is given by

$$
V\left(\bar{y}_{R}\right)-V\left(\bar{y}_{S}\right) \approx \sum_{h}\left(\frac{1}{n}-\frac{W_{h}}{n_{h}}\right) W_{h} s_{h}^{2}+\left(\frac{1}{n}-\frac{1}{N}\right)\left(\sum_{h} W_{h}\left(\bar{Y}_{h}-\bar{Y}\right)^{2}\right)
$$

where $n_{h}=$ sample size in stratum $h$

$$
\begin{aligned}
n & =\sum_{n} n_{h} \\
N_{h} & =\text { number of sampling units in stratum } h \\
N & =\sum_{h} N_{h} \\
W_{h} & =N_{h} / N \\
\bar{Y}_{h} & =\text { population mean in stratum } h \\
\bar{Y} & =\sum_{h}\left(W_{h} Y_{h}\right)
\end{aligned}
$$

and $S_{h}^{2}=$ population variance in stratum $h$.

The first term on the right side of Eq. 1 (termed the allocation component) can be negative, zero or positive, depending on the assigned allocation scheme. The second term on the right side (termed the strata component) will always be greater than or equal to zero. According to Sukhatme and Sukhatme (1970), the difference between the variances (Eq. 1) can be estimated by

$$
\operatorname{Est}\left[v\left(\bar{y}_{R}\right)-v\left(\bar{y}_{S}\right)\right]=\sum_{h}\left(\frac{1}{n}-\frac{W_{h}}{n_{h}}\right) W_{h} s_{h}^{2}+\left(\frac{N-n}{n(N-1)}\right)\left(\sum_{h} W_{h}\left(\bar{y}_{h}-\bar{y}_{s}\right)^{2}-\sum_{h} W_{h}\left(1-W_{h}\right) s_{h}^{2} / n_{h}\right)
$$

where $\bar{y}_{\mathrm{h}}=$ estimated mean abundance in stratum $\mathrm{h}$

$$
\bar{y}_{s}=\sum_{h}\left(W_{h} y_{h}\right)=\text { stratified estimate of population mean }
$$

and $s_{h}^{2}=$ estimated variance in stratum $h$.

The first term on the right side of Eq. 2 is an estimate of the allocation component, and the second term on the right side is an estimate of the strata component. It is more informative to examine the relative efficiency (RE), which is given by

$$
R E=\frac{E s t\left[v\left(\bar{y}_{R}\right)-v\left(\bar{y}_{S}\right)\right] \times 100}{E s t\left[V\left(\bar{y}_{R}\right)\right]}
$$

where, Est $\left[V\left(\bar{y}_{R}\right)\right]=\left(\frac{1}{n}-\frac{1}{N}\right) \sum_{h} W_{h} s_{h}^{2}+\left(\frac{N-n}{n(N-1)}\right)\left(\sum_{h} W_{h}\left(\bar{y}_{h}-\bar{y}_{s}\right)^{2}-\sum_{h} W_{h}\left(1-W_{h}\right) s_{h}^{2} / n_{h}\right)$

Due to the additive nature of the allocation and strata components, the percentage gain (or loss) in efficiency due to each component can be extracted.

\section{Evaluation of Present Scheme}

The history of trawl surveys on the Scotian Shelf (Div. 4VWX) was reviewed by Halliday and Koeller (1981). The present stratification scheme (Fig. 1) was based on depth in recognition of a relationship between large-scale distribution patterns of groundfish species in the region and the hydrographic and bathymetric conditions. It is evident from Table 1 that the prescribed schedule of station allocation to strata in Div. $4 \mathrm{Vs}$ and $4 \mathrm{~W}$ departs from allocation in proportion to stratum size.
Equations 2 and 3 were used to evaluate the present stratification scheme with respect to the precision of the estimated mean catch-per-tow ( $\overline{\mathbf{y}}_{\mathrm{s}}$, numbers) of cod on the eastern Scotian Shelf for the summer (July) surveys in 1970-84. The components, due to allocation and strata effects, are expressed in Fig. 2 as percentages of the estimated variances from random sampling, (Eq. 3). The most striking feature here is the large penalty in precision incurred by the allocation component. This effect was more serious in the 1970's than more recently. Differences in the allocation component are due in part to variation in station allocation by 


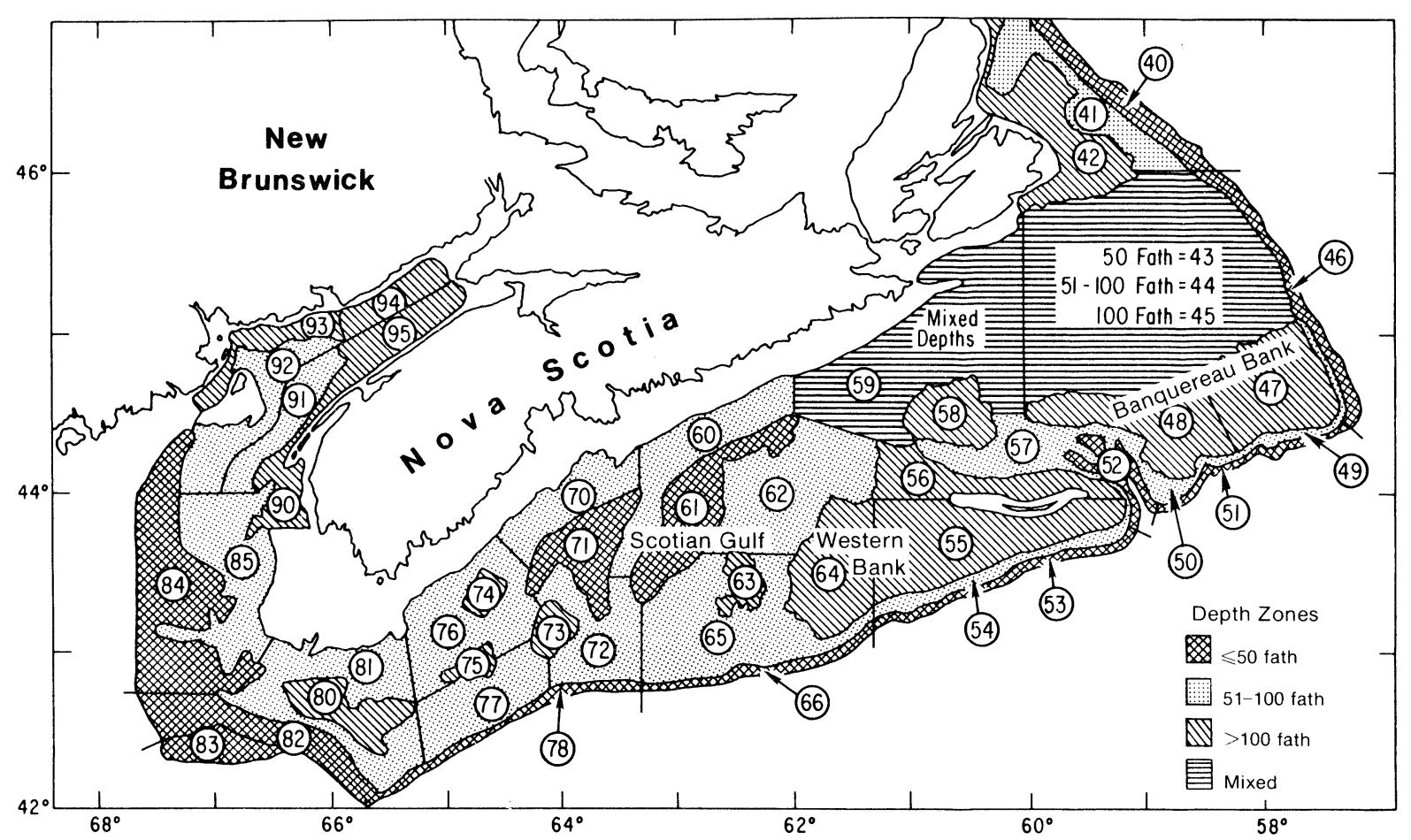

Fig. 1. Present stratification scheme for the Scotian Shelf (Div. $4 \mathrm{VWX}$ ) based on depth.

TABLE 1. Proportion of allocated number of random hauls to stratum size for stratified-random trawl surveys on the Scotian Shelf (Div. $4 \mathrm{Vs}$ and $4 \mathrm{~W}$ ).

\begin{tabular}{|c|c|c|c|c|}
\hline $\begin{array}{l}\text { NAFO } \\
\text { Div. }\end{array}$ & $\begin{array}{c}\text { Stratum } \\
\text { number } \\
\text { (Fig. 1) }\end{array}$ & $\begin{array}{c}\text { Stratum } \\
\text { area } \\
\left(\mathrm{nm}^{2}\right)\end{array}$ & $\begin{array}{c}\text { No. of } \\
\text { hauls } \\
\left(n_{n}\right)\end{array}$ & $\begin{array}{c}\text { Ratio } \\
\mathrm{n}_{\mathrm{n}} / \text { area }\end{array}$ \\
\hline \multirow[t]{10}{*}{$4 \mathrm{Vs}$} & 43 & 1,318 & 4 & 0.003 \\
\hline & 44 & 3,925 & 4 & 0.001 \\
\hline & 45 & 1,023 & 4 & 0.004 \\
\hline & 46 & 491 & 3 & 0.006 \\
\hline & 47 & 1,616 & 4 & 0.002 \\
\hline & 48 & 1,449 & 4 & 0.003 \\
\hline & 49 & 144 & 2 & 0.014 \\
\hline & 50 & 383 & 3 & 0.008 \\
\hline & 51 & 147 & 2 & 0.014 \\
\hline & 52 & 345 & 2 & 0.006 \\
\hline \multirow[t]{14}{*}{$4 W$} & 53 & 259 & 3 & 0.012 \\
\hline & 54 & 499 & 3 & 0.006 \\
\hline & 55 & 2,122 & 7 & 0.003 \\
\hline & 56 & 955 & 6 & 0.006 \\
\hline & 57 & 811 & 2 & 0.002 \\
\hline & 58 & 658 & 3 & 0.005 \\
\hline & 59 & 3,148 & 4 & 0.001 \\
\hline & 60 & 1,344 & 2 & 0.001 \\
\hline & 61 & 1,154 & 2 & 0.002 \\
\hline & 62 & 2,116 & 4 & 0.002 \\
\hline & 63 & 302 & 2 & 0.007 \\
\hline & 64 & 1,297 & 5 & 0.004 \\
\hline & 65 & 2,383 & 5 & 0.002 \\
\hline & 66 & 226 & 3 & 0.013 \\
\hline
\end{tabular}

stratum over the years. It was not always possible to adhere to the prescribed sampling schedule because of bad weather or equipment failure. The large negative

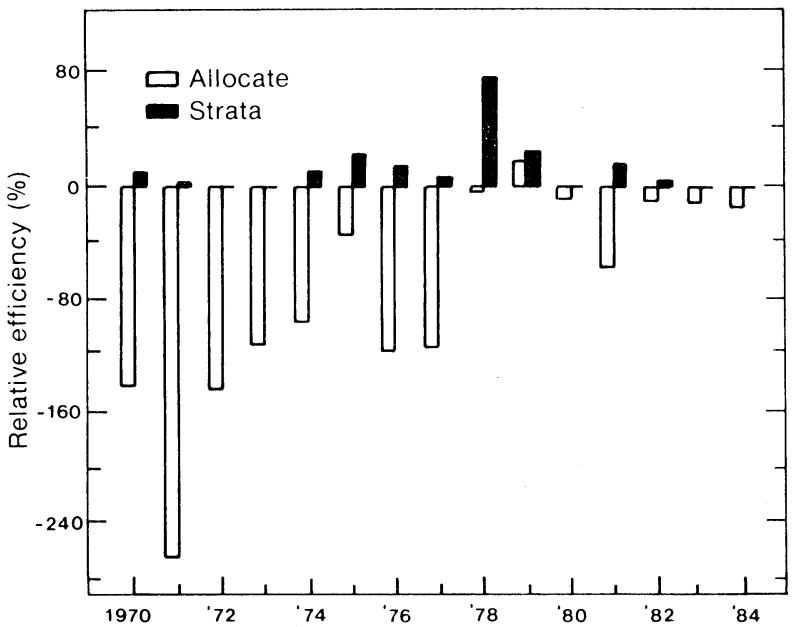

Fig. 2. Percent efficiency of the current stratification relative to simple random sampling, with respect to the allocation and strata components. (Eastern Scotian Shelf cod stock.)

value for 1971 is partly attributable to the fact that only two sets were made in each of the Div. 4Vs strata. In general, the gains due to the strata component were minimal in comparison to the magnitude of the allocation component. The strata component is defined theoretically as a positive quantity, but negative estimates are possible. This appears to occur when the withinstratum variance exceeds the between-stratum variance. Theoretically, stratification is supposed to achieve the opposite effect. The occurrence of a negative estimate may be interpreted as an indication that 
the stratification scheme was ineffectual during the survey in question.

Examination of the decomposition of the gain in precision revealed that, although the large losses due to allocation were mainly in Div. $4 \mathrm{Vs}$, there was no consistent pattern with respect to either area. For any given survey, losses in relative efficiency were generally due to the effect of a few strata on the allocation component.

The present stratification scheme for the eastern Scotian Shelf performs poorly for cod, with respect to precision of abundance estimates, compared to simple random sampling. Improvements can be achieved by restratifying the area so that the strata component is maximized and/or by redesigning the allocation scheme in such a way that the allocation component is equal to or greater than zero. Such improvements are considered in the next section.

\section{Evaluation of an Alternative Scheme}

According to Cochran (1977) the best characteristic for the construction of strata is the frequency distribution of the variable of interest. In the present study, the frequency distribution of the number of adult cod (ages 5-12) is unknown. The next best characteristic is the frequency distribution of another variable which is highly correlated with the variable of interest. The present stratification scheme is based on depth. The use of historical density patterns for the construction of strata was explored, based on the premise that relative density over the study area is similar from year to year. Although distribution patterns may vary from year to year, Scott and Gavaris (MS 1985) concluded that persistent features exist.

To characterize a frequency distribution, it is necessary to have a sufficiently large random sample. The available data for the eastern Scotian Shelf consist of stratified-random samples of about 80 observations per year. Therefore, the data were pooled across strata and over years in order to have a sample large enough for analysis. The ignoring of strata boundaries assumes that departures from a constant sampling probability, imposed by the current stratified design, would not have a significant impact on the analysis. In order to use data for seveal years concurrently, the data from each survey were normalized by dividing each observation by the mean for the survey. In this way, the expected contribution of each observation, with respect to relative density, would be equal. The assumptions and manipulations which were employed to generate a sufficiently large random sample had minimal effect for the purpose to which these results were applied.
In practice, all available data would be used to construct the strata for future surveys. To evaluate the approach, however, the data from surveys in 1970-79 were used to construct strata, and these strata boundaries were then applied to the 1980-84 survey data. Application of new strata boundaries to a sample which was obtained from a stratified-random survey does not take into account the differences in sampling probability that is inherent in the original design. The ratios of number of stations per stratum to area of stratum (Table 1) give some indication of the extent of these differences. Although the values vary from 0.001 to 0.014 , most are between 0.002 and 0.006 . Presently, there is no practical technique which can adjust for this complication, and this deficiency in the analysis is acknowledged.

The construction of new strata involved the partitioning of the frequency distribution of normalized density values for 1970-79. The resultant strata are referred to as F-strata (designated A-F in Table 2). On the basis of this information, the study area was partitioned into geographical units, which are referred to as G-strata (designated 1-6 in Fig. 3). The method described by Cochran (1977, p. 129) was used to define the limits of the normalized density values for the F-strata. This involved tabulating the cumulative square root of the frequency and partitioning it into segments of equal range. Several extreme values of normalized density were excluded in order to facilitate analysis, but this had minimal effect on the outcome. The cumulative square-root frequencies for 1970-74 and 1975-79 showed a similar pattern (Table 2), which, along with the observation that similar spatial dispersion was evident in all years, implied that the spatial patterns for the entire period (1970-79) can be considered together.

Determination of the number of strata to be defined depends upon balancing survey cost considerations against the rate of reduction in the variance as the number of strata is increased. In the present situation, the cost was essentially fixed because the number of stations $(n)$ was fixed. Therefore, the number of strata will be retricted by the necessity of having enough stations per stratum to try different allocation schemes. Analyses by Cochran (1977) indicated that, for constant cost, increasing the number of strata beyond six will seldom be profitable. Six F-strata were used in this study, and 20 class intervals of 0.75 density units each were used in constructing the cumulative square-root frequency (Table 2). The six $F$-strata were designated $A$ to $F$, but $A$ and $B$ could not be partitioned with the degree of resolution that was used in this study. The density limits for these strata are $0.00-0.74(A+B)$, 0.75-1.49 (C), 1.50-2.99 (D), 3.00-5.99 (E), and 6.00-14.99 (F). These F-strata ranges of normalized density were used for plotting the data (Fig. 3). The high degree of small-scale variation did not facilitate 
TABLE 2. Upper and lower limits of normalized density by class for the new F-strata and cumulative square-root frequencies for 1970-74 and 1975-79, relevant to evaluation of surveys for cod on the eastern Scotian Shelf.

\begin{tabular}{|c|c|c|c|c|c|}
\hline \multirow{2}{*}{$\begin{array}{l}\text { New } \\
\text { F-strata }\end{array}$} & \multirow[b]{2}{*}{ Class } & \multicolumn{2}{|c|}{ Density limits } & \multicolumn{2}{|c|}{$\begin{array}{c}\text { Cumulative square-root } \\
\text { frequencies }\end{array}$} \\
\hline & & Lower & Upper & $1970-74$ & $1975-79$ \\
\hline$A+B$ & 1 & 0.00 & 0.74 & 17.4 & 17.0 \\
\hline C & 2 & 0.75 & 1.49 & 23.4 & 23.8 \\
\hline \multirow[t]{2}{*}{$D$} & 3 & 1.50 & 2.24 & 27.4 & 29.0 \\
\hline & 4 & 2.25 & 2.99 & 31.0 & 31.7 \\
\hline \multirow[t]{4}{*}{$E$} & 5 & 3.00 & 3.74 & 33.3 & 34.7 \\
\hline & 6 & 3.75 & 4.49 & 35.0 & 36.7 \\
\hline & 7 & 4.50 & 5.24 & 36.0 & 38.9 \\
\hline & 8 & 5.25 & 5.99 & 37.4 & 39.9 \\
\hline $\mathrm{F}$ & $9-20$ & 6.00 & 14.99 & 43.8 & 48.1 \\
\hline
\end{tabular}

the definition of G-strata boundaries which would correspond exactly to the defined limits of normalized density. Nevertheless, some density-related features are evident (Fig. 3). Specifically, the relative densities were very low in the Scotian Gulf, low on the southern part of Banquereau, high along the northern edge of Western Bank, and variable on the Bank itself. From these observations, three G-strata were defined for each of Div. $4 \mathrm{Vs}$ and $4 \mathrm{~W}$, with division boundaries being maintained (Fig. 3).
The prescribed method of constructing strata could not be followed exactly. In general, there was no guarantee that the F-strata limits, identified by the above method, would correspond to obvious geographical boundaries. However, these F-strata limits were useful as general guidelines for constructing the boundaries of the G-strata.

The relative gain in precision, with respect to simple random sampling for these new strata boundaries was evaluated by assigning the data from the 1980-84 surveys to these new strata. The percentage relative efficiencies from the new design are compared with those from the present design in Fig. $4 \mathrm{~A}$ and $4 \mathrm{~B}$. There was improvement in the allocation component from the new design for 1980, 1981 and 1984, but this component became more negative for 1982 and 1983. The strata component showed little significant change.

The manner by which stations were allocated to strata affected the precision significantly. Under proportional allocation, where the numbers of stations are assigned to strata in proportion to strata size, the relative gain due to the allocation component will be zero. For optimal allocation, where stations are assigned in proportion to the expected variance in each stratum, this component will be positive. Any other allocation

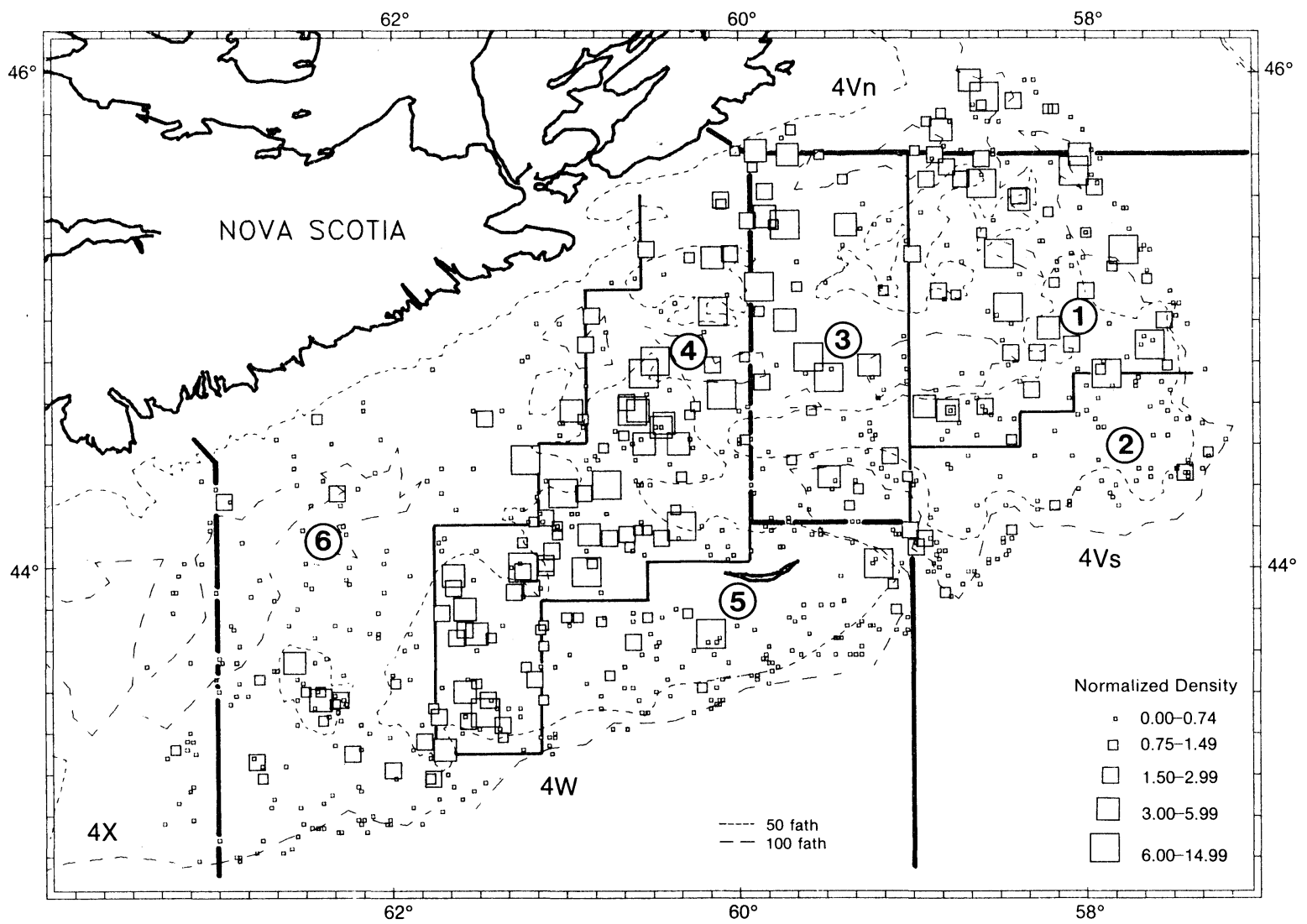

Fig. 3. Normalized density distribution of adult cod on the eastern Scotian Shelf from historical (1970-79) trawl survey data. The boundaries for the alternate strata are also shown. 


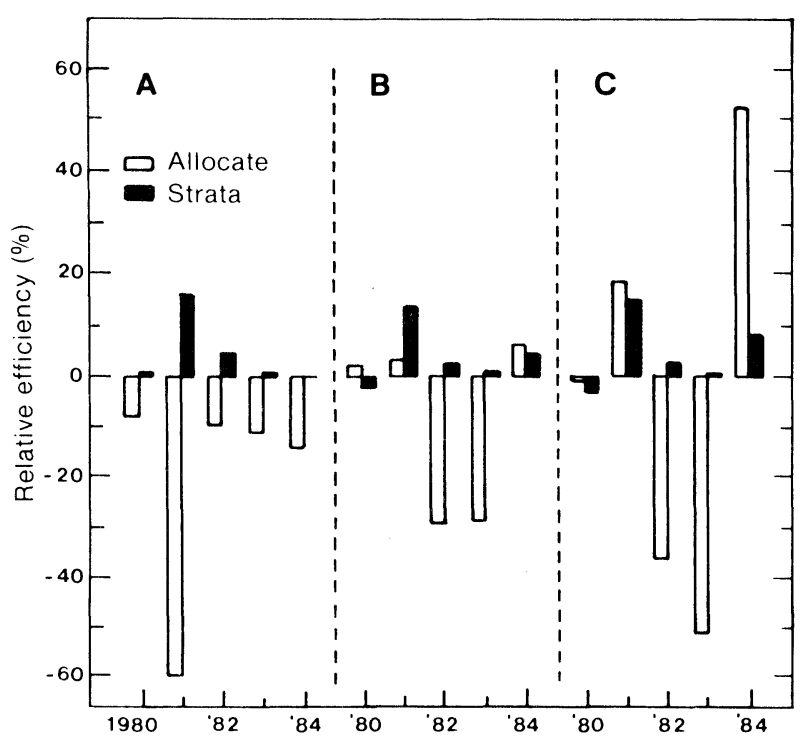

Fig. 4. Comparison of efficiency (percent) of (A) present stratification design, (B) the alternate stratification scheme with an arbitrary allocation scheme and (C) the alternate stratification scheme with an approximately optimal allocation scheme, relative to surveys for cod on the eastern Scotian Shelf. (See text for details of the survey designs.)

scheme will result in a negative value for the allocation component. The effect of applying approximately optimal allocation was investigated.

When means and standard deviations of samples within strata are proportionately related, Hansen et al. (1953, p. 215) showed that an approximately optimal allocation scheme can be achieved by assigning stations to strata in proportion to population size. The relationship between estimated mean catch rates (numbers) and standard deviations for the six strata in all years appears to be linear (Fig. 5). The average for the 1970-79 period was used to define the allocation scheme for 1980-84 (Table 3), because examination of the proportion of the total population occurring in each stratum showed year-to-year variation.

With estimates of the mean and standard deviation which were obtained previously for the new strata, the sample size $\left(n_{h}\right)$ in stratum $h$ was replaced by the total sample size $(n)$ multiplied by the average stratum proportion $\left(p_{n}\right)$ given in Table 3 . Equations 2 and 3 were applied again, and the results are illustrated in Fig. 4C. Application of an approximately optimal allocation scheme resulted in measurable gains over the proportional allocation (Fig. 4B) in 1981 and 1984 and losses in 1980, 1982 and 1983.

\section{Discussion}

The level of precision for abundance indices from bottom-trawl surveys with respect to sample size has

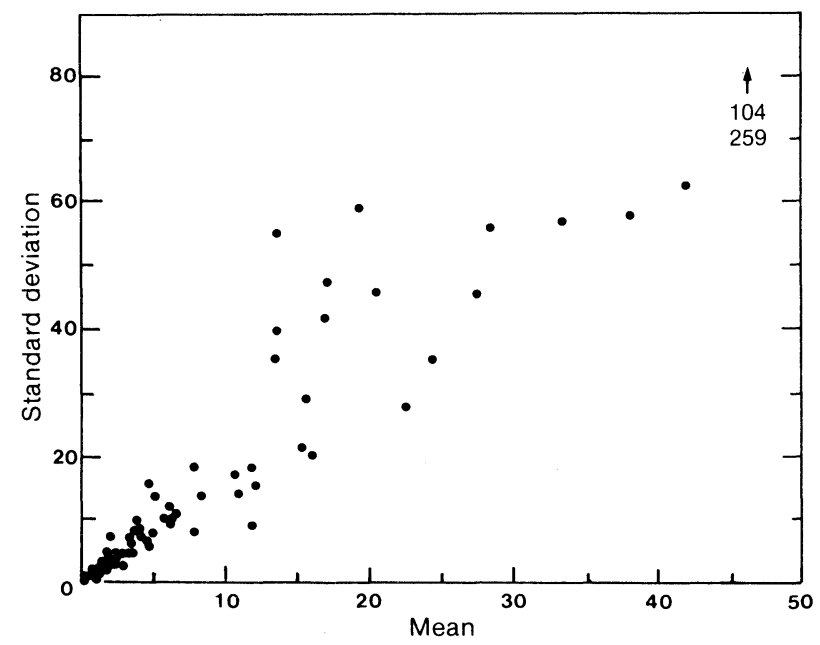

Fig. 5. Proportional relationship between means and standard deviations from the results of the alternate stratification scheme, with respect to cod on the eastern Scotian Shelf (1970-84).

TABLE 3. Estimated proportions of the eastern Scotian Shelf cod population in the new G-strata, based on historical data from summer surveys, 1970-79.

\begin{tabular}{lccccccc}
\hline & \multicolumn{3}{c}{ G-strata in Div. 4Vs } & & \multicolumn{3}{c}{ G-strata in Div. 4W } \\
\cline { 2 - 3 } \cline { 7 - 8 } Year & 1 & 2 & 3 & & 4 & 5 & 6 \\
\hline 1970 & 0.599 & 0.043 & 0.017 & & 0.022 & 0.178 & 0.181 \\
1971 & 0.630 & 0.008 & 0.021 & & 0.076 & 0.203 & 0.062 \\
1972 & 0.635 & 0.020 & 0.042 & & 0.160 & 0.083 & 0.060 \\
1973 & 0.131 & 0.023 & 0.020 & & 0.094 & 0.004 & 0.728 \\
1974 & 0.357 & 0.027 & 0.113 & & 0.104 & 0.077 & 0.321 \\
1975 & 0.263 & 0.122 & 0.139 & & 0.098 & 0.105 & 0.274 \\
1976 & 0.195 & 0.002 & 0.033 & & 0.341 & 0.160 & 0.269 \\
1977 & 0.315 & 0.096 & 0.061 & & 0.138 & 0.074 & 0.315 \\
1978 & 0.046 & 0.034 & 0.033 & & 0.119 & 0.640 & 0.127 \\
1979 & 0.048 & 0.107 & 0.045 & & 0.333 & 0.316 & 0.151 \\
Mean $\left(\mathrm{p}_{\mathrm{h}}\right)$ & 0.318 & 0.048 & 0.053 & & 0.148 & 0.184 & 0.249 \\
Area ${ }^{\mathrm{a}}$ & 3,600 & 2,280 & 3,690 & & 7,465 & 2,600 & 8,400 \\
\hline
\end{tabular}

a Stratum area in nautical square miles $\left(\mathrm{nm}^{2}\right)$.

been examined in several studies (Grosslein, 1971; Jones and Pope, 1973; Pennington and Grosslein, MS 1978). In the present study, the level of precision relative to the variance which would have been obtained by simple random sampling was evaluated, and alternative stratification and allocation schemes based on the use of historical data were explored and evaluated in a similar manner.

The most striking feature of the comparisons is that the present scheme of stratified-random sampling was less efficient than simple random sampling in most years. As noted earlier, arbitrary allocation schemes may result in large losses in efficiency due to the allocation component in Eq. 2 (Sukhatme and Sukhatme, 1970). This result appears to be due primarily to the large numbers of strata and the fixed number of stations, which restrict the options that are available for 
allocation. In contrast, the gains in efficiency due to stratification were generally only marginal.

Comparison of results, relevant to the present and alternative stratification schemes, showed that the relative efficiency due to the strata component did not change significantly when the number of strata was reduced from 24 to 6 . These results indicate that historical data can be used successively to generate meaningful strata boundaries. The results are also indicative of the decreasing gains that were achieved by increasing the number of strata to more than about six (Cochran, 1977). The negligible gains in the allocation component, evident in most years, were possibly due to the allocation being closer to proportional as a result of the larger sample size in each of the six strata. Some improvements were generally noted in the allocation component when approximately optimal allocation was imposed. The observation that the loss due to allocation was greater in some years, however, serves as a warning that interannual spatial variability in abundance could significantly affect the optimal allocation of stations to strata.

The mediocre improvements in precision with the constructed stratification and allocation scheme implies that stratified-random sampling would not be much better than simple random sampling for summer surveys on the eastern Scotian Shelf. It must be noted that the results for the stratification-allocation scheme are not exact due to the variable sampling probability within the new strata. Although it is probable that somewhat improved precision would have been obtained if the designated sampling strategy had been applied, the basic conclusions would still apply. If stratification is required, the recommended strategy would be to use proportional allocation. To achieve this with the present level of sampling, it would be necessary to reduce the number of strata.

The analysis and conclusions of this study are based on the premise that strata are defined by continuous geographical units. It is informative to examine the potential maximum relative efficiency if it were possible to assign membership to a stratum for each sampling unit $\left(2.5^{\prime}\right.$ latitude $\times 2.0^{\prime}$ longitude rectangles) independent of geographical location based on a stratification variable. This approach requires the identification of a stratification variable, which is well correlated with abundance and can be measured over the entire area of interest. With some simplifying assumptions, the maximum gain in relative efficiency from stratification was found to be about $95 \%$ (see Appendix). This compares with an average gain in relative efficiency of $1 \%$ (range -52 to $62 \%$ ) with the stratification-allocation scheme defined for geographical units.

It must be recognized that the evaluation of survey data in this study was based on a single objective, namely, the precision of abundance estimates for adult cod (ages 5-12). There may be other target species and other objectives which would have to be considered in evaluating the overall success of these surveys on the eastern Scotian Shelf.

\section{References}

COCHRAN, W. G. 1977. Sampling techniques. John Wiley and Sons, New York, NY, $428 \mathrm{p}$.

DOUBLEDAY, W. G. (Ed.). 1981. Manual on groundfish surveys in the Northwest Atlantic. NAFO Sci. Coun. Studies, 2: $55 \mathrm{p}$

GAGNÉ, J. A., A. F. SINCLAIR, and L. CURRIE. MS 1983. Status of the $4 \mathrm{VsW}$ cod stock complex. Can Atl. Fish. Sci. Adv. Committee Res. Doc., No. 56, 56 p.

GAGNÉ, J. A., A. F. SINCLAIR, and C. DALE. MS 1984. The 1984 assessment of $4 \mathrm{VsW}$ cod - a completely revised procedure. Can Atl. Fish. Sci. Adv. Committee Res. Doc., No. $78,60 \mathrm{p}$.

GROSSLEIN, M. D. 1969. Groundfish survey program of BCF Woods Hole. Comm. Fish. Rev., 31: 22-30.

MS 1969. Groundfish survey methods. U.S. Nat. Mar. Fish. Serv., Northeast Fisheries Center, Woods Hole Lab. Ref. Doc., No. 69-02, 34 p.

1971. Some observations on accuracy of abundance indices derived from research vessel surveys. ICNAF Redbook, 1971(III): 249-266.

HALLIDAY, R. G., and P. A. KOELLER. 1981. A history of Canadian groundfish trawling surveys and data usage in ICNAF Divisions 4TVWX. In: Bottom trawl surveys, W. G. Doubleday and D. Rivard (ed.) Can. Spec. Publ. Fish. Sci., 58: 27-41.

HANSEN, M. H., W. N. HURWITZ, and W. G. MADOW. 1953. Sample survey methods and theory. Vol. 1. Methods and applications. John Wiley and Sons, New York, NY, 638 p.

ICNAF. 1970. Report of Standing Committee on Research and Statistics. ICNAF Redbook, 1970(I): 3-83.

JONES, B. W., and J. G. POPE. 1973. A groundfish survey of Faroe Bank. ICNAF Res. Bull., 10: 53-61.

PENNINGTON, M. R., and M. D. GROSSLEIN. MS 1978. Accuracy of abundance indices based on stratified-random trawl surveys. ICNAF Res. Doc., No. 77, Serial No. 5264, $42 \mathrm{p}$.

SCOTT, J. S., and S. GAVARIS. MS 1985. Age-related temporal and seasonal changes in distribution of cod on the eastern Scotian Shelf. NAFO SCR Doc., No. 92, Serial No. N1067, 9 p.

SINCLAIR, A., and S. GAVARIS. MS 1985. Sequential population analysis of $4 \mathrm{VsW}$ cod following the 1984 fishery. Can. Atl. Fish. Sci. Adv. Committee Res. Doc., No. 48, 28 p.

SUKHATME, R. V., and B. V. SUKHATME. 1970. Sampling theory of surveys with applications. lowa State Univ. Press, Ames, lowa, $452 \mathrm{p}$. 


\section{Appendix. Potential Relative Efficiency}

Developed here is an estimate of the potential relative efficiency for stratification which is independent of geographical location of the sampling units. Since the measure of efficiency is relative, it will be sufficient to evaluate the maximum relative efficiency for the normalized density. A measure of $W_{h}$ for optimal stratification is provided by assuming that the observed frequency of the normalized density (preceding Table 2) is representative of the population. It is further assumed that, for each partition in Table 2, the distribution can be approximated by a uniform distribution. Thus, an estimate of the mean is

$$
\bar{y}_{h}=\left(y_{h l}+y_{h u}\right) / 2
$$

where $y_{h l}$ and $y_{h u}$ are the lower and upper limits in stratum $h$. An estimate of the standard deviation is

$$
s_{h}=\sqrt{12}\left(y_{n u}-y_{n 1}\right)
$$

Noting that

$$
\text { Est }\left[\mathrm{V}\left(\overline{\mathrm{Y}}_{\mathrm{R}}\right)-\mathrm{V}\left(\overline{\mathrm{Y}}_{\mathrm{s}}\right)\right]=\operatorname{Est}\left[\mathrm{V}\left(\overline{\mathrm{y}}_{\mathrm{R}}\right)\right]-\operatorname{Est}\left[\mathrm{V}\left(\overline{\mathrm{y}}_{\mathrm{s}}\right)\right]
$$

equation (3) in the "Method of Evaluation" section was applied by using

$$
\text { Est }[V(\bar{y} s)]=\frac{1}{n}\left(\sum_{h} W_{h} S_{h}\right)^{2}-\frac{1}{N}\left(\sum_{h} W_{h} s_{h}{ }^{2}\right)
$$

Equation (A4) is the estimate of the variance under Neyman allocation, and $n_{n}$ values are computed as follows:

$$
\mathrm{n}_{\mathrm{h}}=\frac{\mathrm{nW} \mathrm{W}_{\mathrm{h}}}{\sum_{\mathrm{h}} \mathrm{W}_{\mathrm{h}} \mathrm{S}_{\mathrm{h}}}
$$

The resulting gain in relative efficiency was about $95 \%$, based on estimates of $W_{h}, \bar{y}_{h}$ and $s_{h}$ from the normalized density values for $1970-79$, and with the sample size $(n)$ of 80 . 